\title{
AZUFRADO BOLITA, NUEVA VARIEDAD DE FRIJOL PARA EL ESTADO DE JALISCO, MÉXICO
}

\section{AZUFRADO BOLITA, A NEW DRY BEAN CULTIVAR FOR THE STATE OF JALISCO, MÉXICO}

\author{
Rogelio Lépiz-Ildefonso ${ }^{*}$, José de J. López-Alcocer ${ }^{1}$, \\ Carlos González-Rivas ${ }^{2}$ y Eduardo Rodríguez-Guzmán'
}

\begin{abstract}
'Universidad de Guadalajara, Centro Universitario de Ciencias Biológicas y Agropecuarias. Camino Ramón Padilla Sánchez 2100, Nextipac, Zapopan, Jalisco. ${ }^{2}$ Instituto Nacional de Investigaciones Forestales, Agrícolas y Pecuarias. Campo Experimental Santiago Ixcuintla. Carretera Internacional México-Nogales Kilómetro 6, Santiago Ixcuintla, Nayarit.

*Autor para correspondencia (rlepiz@cucba.udg.mx)
\end{abstract}

El estado de Jalisco destacó en México como productor de frijol (Phaseolus vulgaris L.) en la segunda mitad del siglo pasado, pero en los años de 2000 a 2014 registró una producción significativamente menor, periodo en el que se cosechó un promedio anual de 19,347 ha con una producción de 17,855 t de grano (SIAP, 2015) y se importaron alrededor de 60,000 t por año para cubrir la demanda estatal de frijol.

Una opción para rescatar la producción estatal de frijol, reducir el nivel de importaciones y contribuir a la producción nacional, es promover el cultivo de frijol arbustivo en zonas agroecológicas con condiciones favorables, como las regiones Centro, Sur, Valles y parte de los Altos de Jalisco. En estas zonas existen los elementos de clima y suelo apropiados para la producción agrícola, donde se ha demostrado que bajo condiciones de temporal (secano) y manejo tecnificado del cultivo, se pueden cosechar hasta 2 t ha-1 $^{-1}$ de grano de frijol (Lépiz et al., 2001).

En virtud del panorama precedente y dada la necesidad de actualizar algunos componentes tecnológicos con 20 o más años de haberse obtenido, así como de generar nuevas tecnologías para la producción moderna de frijol en regiones con potencial productivo, la Universidad de Guadalajara (UDG) puso en marcha un proyecto de investigación en frijol orientado principalmente al desarrollo de variedades de alto rendimiento y grano preferente.

El proyecto se inició con la introducción de germoplasma nacional e internacional, para identificar progenitores fuente de genes de adaptación, resistencia a bacteriosis de halo (Pseudomonas syringae pv. phaseolicola) y antracnosis (Colletotrichum lindemuthianum), para mejorar por hibridación y selección las variedades de frijol tipo Peruano de Sinaloa, cultivares de alta demanda en Jalisco por consumidores y productores, pero con problemas de adaptación y susceptibilidad a las enfermedades ya mencionadas (Lépiz et al., 2001).
Para la obtención de esta nueva variedad se utilizó el método de hibridación y selección. La línea AND 277 de frijol rojo moteado adaptada a Jalisco, resistente a las enfermedades mencionadas y de semilla grande (44 g en 100 semillas), se cruzó con la variedad sinaloense Peruano Bola Grande también de grano grande (43 g en 100 semillas). Las hibridaciones para producir las combinaciones genéticas deseadas (adaptación, resistencia a enfermedades, rendimiento y grano preferente), se realizaron en 2001 y 2002. En los años de 2003 a 2008 se llevó a cabo el avance generacional y selección en la población segregante obtenida. La selección de líneas puras se realizó mediante la combinación del método genealógico aplicado en ciclos primavera-verano en Zapopan y el método masivo ("bulk breeding") (Singh, 1998; Gepts y Hancock, 2006), en siembras efectuadas en otoño-invierno en el Campo Experimental de Santiago Ixcuintla, Nayarit, del Instituto Nacional de Investigaciones Forestales, Agrícolas y Pecuarias.

Las líneas puras de frijol tipo Peruano, base de la nueva variedad, se obtuvieron entre 2006 y 2009. La primera evaluación de las líneas por adaptación y rendimiento, se realizó entre 2006 y 2010 en la estación experimental Las Agujas de Zapopan, Jalisco (Cuadro 1). Los materiales seleccionados en el campo experimental por resistencia a enfermedades, adaptación, tipo de grano y buen rendimiento, se evaluaron en un ensayo de rendimiento regional entre 2011 y 2012 (Cuadro 2), y luego en parcelas de validación en campos de productores durante el 2013.

Se hizo también la caracterización de las líneas con altas posibilidades de registro conforme a los descriptores de SNICS (2013) basados en los principios de la Unión Internacional para la Protección de Obtenciones Vegetales (UPOV, 2015). Finalmente, en 2014 se solicitó al Servicio Nacional de Inspección y Certificación de Semillas (SNICS) el registro como nueva variedad de la línea CBA-7-23-M30-M de frijol tipo Peruano bola, línea derivada de la cruza AND 277 x Peruano Bola Grande con código UGPB-1. El 
Cuadro 1. Desempeño agronómico de variedades de frijol en Zapopan, Jalisco, durante el ciclo Primavera-Verano 2007.

\begin{tabular}{lccccccccc}
\hline Línea & $\begin{array}{c}\text { Días a } \\
\text { floración }\end{array}$ & $\begin{array}{c}\text { Días a } \\
\text { madurez }\end{array}$ & ADV & $\begin{array}{c}\text { Reacción } \\
\text { PHY }\end{array}$ & $\begin{array}{c}\text { Reacción } \\
\text { BC }\end{array}$ & $\begin{array}{c}\text { Reacción } \\
\text { ANT }\end{array}$ & VAG & TC (min) & $\begin{array}{c}\text { Rend. } \\
\left(\mathrm{kg} \mathrm{ha}^{-1}\right)\end{array}$ \\
\hline UGAP-5 & 40 & 88 & 3.7 & 1.7 & 2.0 & 2 & 2.0 & 115 & 1803 \\
Azufrado Bolita & 42 & 86 & 4.0 & 3.3 & 3.7 & 2 & 3.0 & 117 & 1901 \\
A. Higuera (T) & 40 & 85 & 6.0 & 8.0 & 7.0 & 7 & 7.7 & 110 & 678 \\
\hline
\end{tabular}

Escala de evaluación (variables agronómicas y patológicas): 1, 2, 3 = bueno/resistente; 4, 5, 6 = intermedio; 7, 8, $9=$ deficiente/susceptible. ADV = adaptación vegetativa (vigor de la planta); $\mathrm{PHY}=$ (Phytophthora phaseoli); BC = bacteriosis común; $\mathrm{ANT}=$ antracnosis; $\mathrm{VAG}=$ valor agronómico (vigor, sanidad, potencial de rendimiento); TC = tiempo de cocción; Rend. = rendimiento; . Higuera = Azufrado Higuera; $T$ = variedad testigo.

Cuadro 2. Rendimiento de grano $\left(\mathrm{kg} \mathrm{ha}^{-1}\right)$ de variedades de frijol, en cinco ambientes de temporal (secano) del estado de Jalisco, México.

\begin{tabular}{lcccccc}
\hline \multirow{2}{*}{ Línea } & Ixtlahuacán & Zapopan & Zapopan & Zapopan & Zapopan & Promedio \\
\hline UGAP-16 & 2011 & 2011 & 2011 & 2012 & 2012 & 1460 \\
Azufrado Bolita & 1575 & 1254 & 880 & 1932 & 1659 & 1043 \\
Azufrado Higuera $(T)$ & 976 & 887 & 756 & 1481 & 1114 & 552 \\
DMS $_{0.05}$ & 770 & 366 & 366 & 739 & 521 & 243 \\
\hline
\end{tabular}

UGAP-16 es una línea experimental de tipo Peruano en proceso de evaluación. El ensayo completo incluyó 20 genotipos de frijol evaluados en localidades del estado de Jalisco. $\mathrm{DM}_{0.05}$, diferencia mínima significa con 0.05 de probabilidad de error.

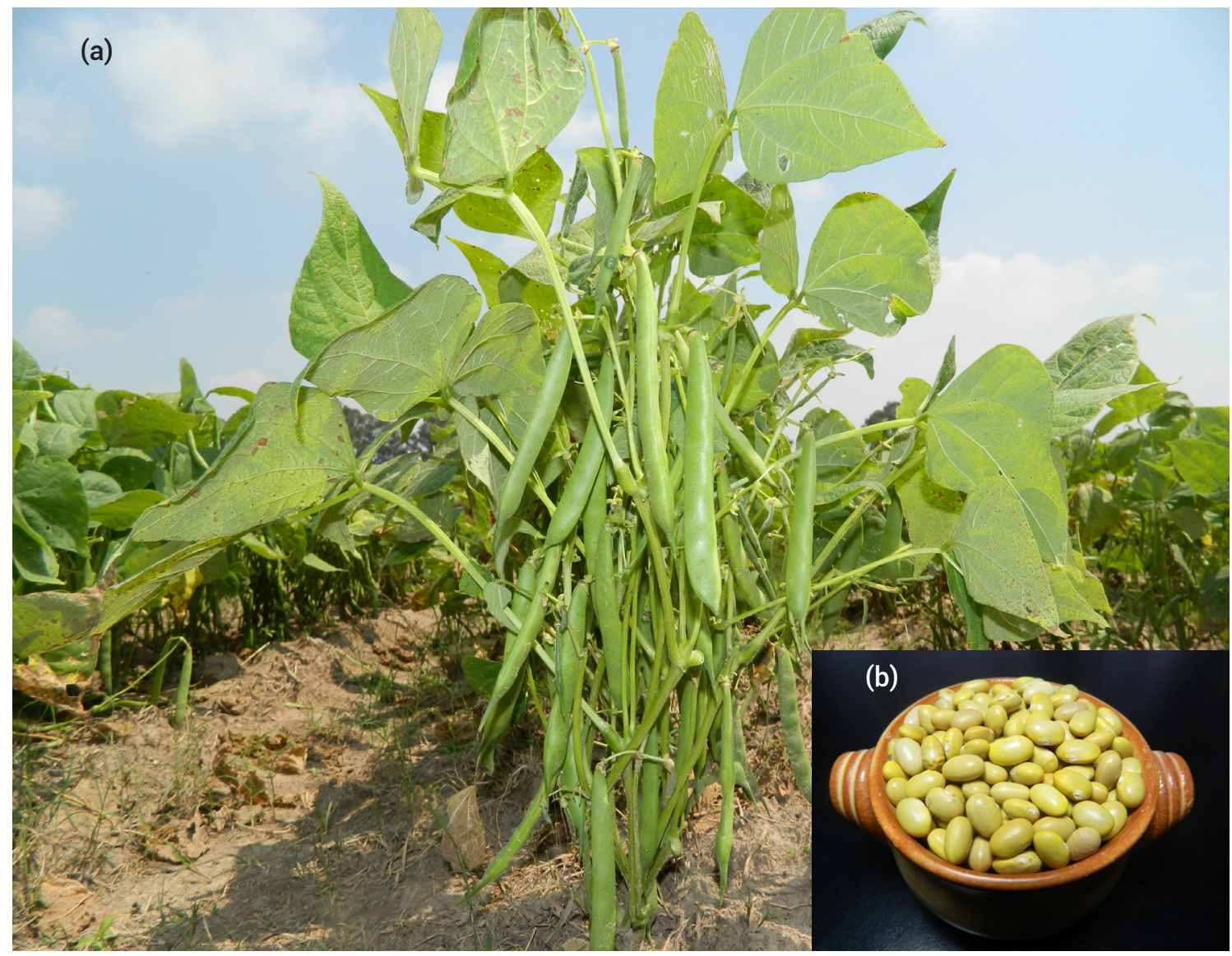

Figura 1. Plantas de frijol Azufrado Bolita en etapa de llenado de vainas (a), y sus granos (b). 
título de obtentor se emitió en enero de 2015 con registro 1305 y nombre oficial de Azufrado Bolita.

La variedad Azufrado Bolita es de hábito de crecimiento determinado tipo 1a (Figura 1a), ciclo biológico intermedio (42 d a floración y 94 d a madurez), resistente a la infección natural en el campo por roya (Uromyces appendiculatus), bacteriosis de halo y antracnosis (Cuadro 1). El grano es amarillo suave (azufrado) sin color alrededor del hilio, de forma ovoide, con un peso de $35 \mathrm{~g}$ en 100 granos (Figura 1b) cuyo tiempo de cocción es similar al de la variedad testigo (Cuadro 1). Para las condiciones de temporal (secano) en las regiones Centro, Valles, Sur y Altos de Jalisco (Ixtlahuacán del Río, Cuquío, Yahualica), Azufrado Bolita debe sembrarse entre el 25 de julio y el 10 de agosto, a una densidad de 15 semillas por metro lineal en surcos a 75 cm de separación; fertilizar a la siembra con 50N-50P-0K y realizar un eficiente control de maleza y de plagas (Lépiz et al., 2015). Se dispone de semilla en el Centro Universitario de Ciencias Biológicas y Agropecuarias (CUCBA), ubicado en Zapopan, Jalisco.

\section{BIBLIOGRAFÍA}

Gepts P. y J. Hancock (2006) The future of plant breeding. Crop Science 46:1630-1634.

Lépiz R., E. López, J. L. Martínez, R. Rodríguez, S. de la Paz y M. Morales (2001) Desarrollo de variedades de frijol para el occidente de México. Scientia-CUCBA 3:86-93.

Lépiz R., S. Sánchez, E. López, J. J. López, I. E. Chavarín y K E. Meza (2015) El Cultivo de Frijol en Jalisco. Tecnología para Altos Rendimientos. UDG, CUCBA. Zapopan, Jalisco, México. 54 p.

SIAP, Servicio de Información Agroalimentaria y Pesquera (2015) Anuario Estadístico de la Producción Agrícola. Cierre de la producción agrícola por cultivo en Jalisco. http:/www.siap.gob.mx. (Julio 2015).

Singh P. S. (1998) Mejora genética de los frijoles de la Raza Mesoamérica para el trópico: las realidades, los retos y sugerencias. In: R. Lépiz-Ildefonso (ed.) Taller Internacional de Mejoramiento Genético de Frijol Negro Mesoamericano. Memoria. PROFRIJOL, Veracruz, México. pp:101-114

SNICS, Servicio Nacional de Inspección y Certificación de Semillas (2013) Guía Técnica para la Descripción Varietal de Frijol (Phaseolus vulgaris L.). Tlalnepantla, Estado de México, México. 24 p.

UPOV, Unión Internacional para la Protección de las Obtenciones Vegetales (2012) Directrices para la Ejecución del Examen de la Distinción la Homogeneidad y la Estabilidad. Judía común (Phaseolus vulgaris). Ginebra, Suiza. 47 p. http://www.upov.int/edocs/tgdocs/es/tg012.pdf (Febrero 2016) 